\title{
ARISTIDES E AS CIDADES: A ATÉLEIA E A EVASÃO DAS LITURGIAS NA ÁSIA MENOR, CA. 170 E.C.
}

Profa. Dra. Lolita Guimarães Guerra ${ }^{1}$

\begin{abstract}
Resumo: As formas de evasão das responsabilidades para com a coisa pública permitem, para alguns indivíduos com os recursos adequados, privilégios e isenções que os retiram do lugar ocupado pela multidão dos 'comuns', estes submetidos por igual a leis e com acesso ao mesmo corpo de direitos que os normaliza nas dinâmicas da vida cotidiana. Élio Aristides, baseado em Esmirna, foi indicado a diversas liturgias entre as décadas de 140 e 150 E.C., como mais tarde relatou nos Hieroì Lógoi. Por meio delas, a província e as cidades procuravam garantir a administração de diversos setores da vida social através de custosos encargos atribuídos a particulares. Como não fazia parte do grupo de profissionais isentos por lei, Aristides apelou a sua rede de influências pessoais, a qual incluía o imperador Marco Aurélio, e por meio dela teve a atéleia (imunidade) garantida. Discutiremos os recursos políticos assim utilizados por ele e os significados e efeitos de sua evasão.
\end{abstract}

Palavras-chave: Élio Aristides; liturgias; atéleia; redes de influência.

\section{INTRODUÇÃo}

Os Hieroì Lógoi de Élio Aristides compõem uma autobiografia redigida na década de $170^{2}$, a qual inclui viagens, curas, disputas políticas e atividades profissionais relatadas como experiências extraordinárias e de ordem sobrenatural. Muitos anos antes de sua escrita, Aristides adoecera gravemente e, ao falharem os tratamentos mundanos, se voltara à devoção a Asclépio. A partir desse momento, ele entregou-se a uma rotina de prescriçóes reveladas em sonhos pelo deus e às suas orientações profissionais. Aristides internou-se

\footnotetext{
1 Doutora em História pela Universidade Estadual de Campinas. Professora de História Antiga da Faculdade de Formação de Professores da Universidade Estadual do Rio de Janeiro. Endereço eletrônico: lolitagg@gmail.com.
}

2 Salvo quando explicitamente informado, todas as datas são relativas à Era Comum. 
por cerca de dois anos no Asclepeion de Pérgamo para dedicar-se às terapias. Durante esse tempo manteve-se recluso, afastado da esfera pública. Já no santuário, lentamente e sob a orientação de Asclépio, retomou os exercícios retóricos e voltou a discursar.

Os Hieroì Lógoi são simultaneamente uma aretalogia e uma autobiografia, e esses gêneros literários ali se amparam por meio de seus instrumentais retóricos ${ }^{3}$. A obra se apresenta explicitamente como um discurso em exaltação aos poderes e benefícios de Asclépio, mas a fim de atribuir autenticidade e eficiência à narrativa como um todo, Aristides recorre ao relato majoritariamente verossímil de sua história de vida. Assim, os episódios sobrenaturais dos Hieroì Lógoi revestem-se de um verniz de autenticidade para uma audiência que assume como verdadeiras as narrativas sobre suas peripécias grandiosas, porém mundanas. Por outro lado, o caráter aretalógico da obra, ao celebrar os favores e o poder de Asclépio, exalta igualmente Aristides e o remove da esfera pública. A narrativa constrói a própria relevância ao fazer de seu autor-protagonista alguém alienado do mundo dos 'comuns', um indivíduo extraordinário e de poderes sobrenaturais. Segundo a dinâmica própria ao gênero autobiográfico instrumentalizado por recursos aretalógicos, o texto produz um Aristides que muito pouco tem a ver com a coletividade da qual faz parte, mas encontra-se para além até mesmo de seu já bastante privilegiado contexto social. Porém, nem sempre os favores de Asclépio e suas habilidades em elogiar a si mesmo foram suficientes para mantê-lo plenamente alienado do mundo dos homens, e de fato seu objetivo não parece ter sido o isolamento total.

Aristides deseja ser reconhecido, circular em meios politicamente poderosos e participar de suas prerrogativas. Além disso, seu lugar social o faz acreditar que lhe é devida a isenção de obrigações que em condições normais recairiam sobre si. Como um protegido do deus e por sua profissão - a profissão de um homem de elite - ele não admite ser conclamado a ocupar funções na cidade que lhe serão dispendiosas em termos de tempo e de riqueza, apesar delas serem, justamente, parte das exigências públicas que recaem sobre homens em posição análoga à dele. Nos Hieroì Lógoi, ele narra como conseguiu evadir-se desses compromissos lançando mão de uma providencial rede de influências, cujos encaminhamentos são interpretados como se sob auspícios divinos. Como em tantos momentos ao longo de nossas histórias como comunidades humanas, um homem já favorecido pelo seu lugar

$3 \mathrm{O}$ caráter aretalógico e autobiográfico dos Hieroì Lógoi foi destacado, principalmente, por Copete, tradutor da obra (1999, p. 248), Israelowich (2012, p. 26), Marie-Henriette Quet (1993) e Jacques Bompaire (1993). 
de nascimento busca todos os meios de assegurar privilégios excepcionais para si e de negar ao público aquilo que lhe é formalmente devido.

\section{O contexto de formação de Aristides}

Élio Aristides nasceu na Mísia Oriental, poucos anos antes dessa região da Ásia Menor ser tomada pelo amplo empreendimento de reorganização e urbanização impulsionado por Adriano nos anos 120 (BOWERSOCK, 1969, p. 70). Uma das consequências foi a substituição das antigas entidades políticas por cidades de características gregas, como Adrianuteras e Adriani, próximas de Pérgamo, uma delas o local de nascimento de Aristides (GUERRA, 2014, p. 27-30). A principal propriedade de sua família ${ }^{4}$, à qual o imperador atribuíra a cidadania romana, ficava próxima a um templo de Zeus Olímpio na colina de Átis, a leste do rio Macesto (Hieroì Lógoi 1.43; 3.16, 40ss; 4.1, 48s; BEHR, 1968, 4-8). Aristides busca desconstruir qualquer possibilidade inserção pública em sua cidade de origem ao produzir uma memória sobre seus vínculos não com ela, mas com Esmirna. Quando o procônsul Severo nomeia-o irenarca ${ }^{5}$, para evadir-se dessa liturgia, Aristides a identifica como 'uma cidade da Mísia que não é necessário nomear', enquanto Esmirna, por sua vez, tivera o direito de propor seu nome 'muito antes daquela ter esperanças de se tornar uma cidade' (HL 4.72s). Como veremos, nem mesmo com Esmirna Aristides sustentou uma posição na política formal, ao ser solicitado para isso.

O contexto de criação de Aristides situa-o numa elite agrária pródiga de recursos para dotá-lo de sucessivos preceptores: Epágato, Nérito e o médico Zósimo (HL 4.54; 3.15; 1.75; 2.9). Assim, mais tarde ele foi discípulo de Alexandre de Cotieu e também pode ter tido homens como Heródes Ático, Arístocles e Pólemon por mestres, ou ao menos a oportunidade de ouvi-los em Atenas, Pérgamo e Esmirna (ARISTIDES, Epitáfio a Alexandre 2; FILÓSTRATO, Vidas dos Sofistas 581; Suda 1.3902). Filóstrato observa que ele pode ter sido filho de Eudemo, um rico proprietário de terras na custosa posição de sacerdote do culto a Zeus Olímpio (FILÓSTRATO, VS

4 Behr (1968, p. 4-8) faz um levantamento das propriedades sob responsabilidade de Aristides e sua provável localização. As de origem familiar estendiam-se entre o rio Esepo e o lago Apoloniatis. A sudoeste da área do templo de Zeus Olímpio, no caminho para Adrianuteras, encontrava-se o Laneu (HL 4.105), mais uma fazenda (HL 1.75) e, às margens do Esepo, uma quarta propriedade. Além disso, ele detinha casas em Esmirna, tanto em seu centro urbano quanto nas periferias da cidade (HL 2.38s; 2.43).

5 Responsável pela manutenção da paz (ordem pública) a ser nomeado pelo procônsul da província (COPETE, 1999, p. 390). 
581). Essa identidade não é confirmada por Aristides, porém ele faz contínuas referências à propriedade familiar e sua proximidade do templo de Zeus, indícios favoráveis a uma íntima relação com a estrutura sacerdotal local ${ }^{6}$. Sua família, seus amigos e sua entourage de preceptores e intelectuais de renome indicam um lugar social de mobilidade e acesso a prestigiosos bens simbólicos, na forma principalmente de uma rede de pessoas às quais pode solicitar recursos políticos em momentos de tensão.

\section{A Narrativa da atéleia}

As liturgias faziam parte das antigas práticas gregas por meio das quais setores privilegiados da sociedade assumiam cargos públicos e os custos relativos ao seu desempenho. Se, por um lado, elas ofereciam boas oportunidades de exposição e afirmação de prestígio por particulares, por outro, eram caracteristicamente onerosas. Aristóteles já havia sinalizado esses aspectos ao criticar os oligarcas que se negavam a ocupar cargos e a oferecer banquetes e monumentos públicos, pois assim fragilizavam o apoio popular sobre o qual sustentavam-se e não aproveitavam a oportunidade de construírem uma memória positiva sobre si mesmos (ARISTÓTELES, Política, 1321a). Moses Finley observa a ancestralidade da liturgia como uma patronagem comunitária de caráter honorífico e compulsório, a qual remetia a uma ampla gama de dimensões religiosas, como a construção e restauração de santuários e o financiamento de festivais e suas exibições atléticas e teatrais $(1983,35$ s). Em meados do século IV a.E.C. em Atenas, havia cerca de uma centena de compromissos públicos anuais, aos quais os nomeados poderiam requerer imunidade, e a cidade chegou a aprovar (talvez apenas temporariamente) uma lei contrária às isenções a fim de garantir os fundos para os festivais (DAVIES, 1967, p. 40; DEMÓSTENES, Contra Leptino). Na época de Aristides, alguns setores profissionais tinham imunidade assegurada (atéleia), como era o caso dos médicos ${ }^{7}$ e dos professores de retórica, segundo inscrições em Pérgamo e Éfeso dos reinados de Vespasiano e de Trajano (Israelowich, 2014, 238). Mais tarde, Adriano declarou filósofos, oradores, gramáticos e médicos como isentos de uma série de encargos e magistraturas (Digesta,

6 Quanto ao posicionamento dos especialistas a esse respeito, ver Guerra (2014, p. 32). Suas propriedades e o templo são mencionados em HL, 1.43; 3.13, 16, 20, 41; 4.1-2, 21, 28, 48-49; $5.10,47$.

7 A atéleia dos médicos é sugerida por Dion Cássio (53.30), segundo o qual Augusto instituíra imunidades fiscais para os companheiros de profissão de Antônio Musa após ele tê-lo curado de uma grave enfermidade. Todavia, a passagem não é conclusiva em relação à antiguidade da imunidade geral efetivamente explícita nas inscrições pergamenas e efésias. 
27.1.6.8). A lei foi alterada por Antonino Pio no sentido de limitar o número de profissionais imunes por cada cidade, porém agora com a ambígua cláusula

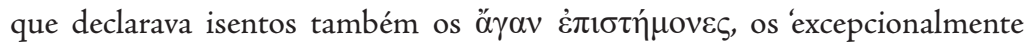
instruídos' (Digesta 27.1.6.2; 27.1.6.10).

Entre as décadas de 140 e 150, Aristides foi apontado coletor de impostos e sumo sacerdote do culto imperial na província (HL 4.96; 4.101), prítano e sacerdote de Asclépio em Esmirna (HL 4.88; 4.102), e irenarca ${ }^{8}$ de sua cidade de origem (HL 4.72). A narrativa encontra-se invertida: a nomeação a irenarca, ocorrida sob o proconsulado de Severo (152-153), é a primeira a ser relatada, acompanhada da pritania, da qual Aristides se esquivou durante o mesmo processo. A atéleia foi conquistada devido a cartas enviadas por pessoas influentes e pelos imperadores, mas Aristides construiu a narrativa de maneira a sugerir que foi Asclépio quem primeiro interviu em seu benefício e, em última instância, o responsável pelo apoio político recebido. Ele afirma ter pedido orientaçóes ao deus quanto às nomeaçóes, e em resposta recebera um oráculo délfico, interpretado como uma referência às cartas de Antonino Pio e Marco Aurélio e de Heliodoro (ex-prefeito do Egito), decisivas para a solução do caso (HL, 4.75-76). A inversão da ordem narrativa faz parecer espontânea a intervenção dos imperadores, porém, cerca de um ano antes, quando nomeado coletor de impostos, Aristides apelara a Roma (DOWNIE, 2008, p. 185; HL, 4.96). Desta forma, as cartas emitidas na época da disputa com Severo eram respostas a apelos anteriores, mas os Hieroì Lógoi as interpreta como um efeito do favorecimento divino.

Em termos cronológicos, a primeira nomeação ocorreu logo que Aristides retornou de seu período de internação no Asclepeion de Pérgamo, ao final dos anos 140 (DOWNIE, 2008, 186). Aristides foi indicado pela assembleia reunida em Esmirna como sumo sacerdote do culto imperial, contudo, segundo ele, devido às suas habilidades retóricas, a indicação foi retirada $(\mathrm{HL}$, 4.100-102). Em seguida, a assembleia tentou persuadi-lo a assumir o cargo de sacerdote de Asclépio na cidade, mas a nomeação foi novamente retirada devido a sua condição de devoto do deus:

Eu sabia que teria êxito com minha resposta. Disse que não podia fazer qualquer coisa, grande ou pequena, sem o consentimento do deus, e que não considerava lícito exercer o sacerdócio sem tê-lo consultado. Todos ficaram impressionados com minhas palavras e demonstraram consentimento. Depois disso, meus discursos obtiveram fama e renome, e acreditei que tudo estivesse terminado (HL, 4.102).

$8 \mathrm{Na}$ época de Aristides, em Esmirna, o cargo relacionava-se a funções administrativas e era atribuído diretamente pela assembleia (CADOUX, 1938, p. 192). 
Anos depois, Aristides foi indicado a coletor de impostos de Esmirna (151-152). Essa indicação ocorreu em sua ausência, e ele a considerou bastante inconveniente, tanto por ter chegado apenas recentemente à cidade, quanto por seu interesse em atuar como orador e professor:

Um sucesso parecido ocorreu aproximadamente um ano antes, quando Pólio era procônsul da Ásia. Não fazia muito tempo, havia me apresentado diante da assembleia, após um longo período de inatividade, porque o deus, como eu disse, me animava a retornar à oratória. Todos esperavam que eu ensinasse aos jovens. Os maus sofistas estavam cheios de medo, certamente não todos, mas os que tinham motivos de preocupação. Fui eleito coletor de impostos e levei o assunto ao legado do governador, que confirmou a nomeação nos tribunais de Filadélfia, ainda que na minha ausência. Depois disso, a decisão do legado foi lida à assembleia. Apresentamos um recurso de apelação a Roma e enviamos cartas tanto ao próprio Pólio quanto ao seu legado, onde expúnhamos os argumentos convenientes (HL, 4.94-96).

Aristides desvencilhou-se da nomeação por meio de cartas de sua autoria, nas quais possivelmente fazia referência ao processo anterior ( $\mathrm{HL}$ 4.98). Observamos nessa segunda nomeação seu argumento quanto a priorizar atividades profissionais, aparentemente respaldado na legislação antonina. Todavia, Aristides não assumiu alunos, como pouco tempo depois demonstraram as nomeações sob o proconsulado de Severo. Quando nomeado irenarca de sua cidade natal, ele apelou a amigos bem relacionados (como Lúcio Rufino e Cláudio Pardalas) e advogados a fim de desvencilharse da convocação ( $\mathrm{HL}, 4.73,83 \mathrm{~s}$ ). Ao longo desse processo Aristides recebeu as cartas enviadas pelos imperadores e por Heliodoro emitidas na época do processo anterior, e cuja chegada interpretou como um prodígio divino:

Chegou a tarde e perguntei ao deus o significado de tudo aquilo significava e o que eu deveria fazer. Recebi esses versos do oráculo de Delfos: Eu e as brancas virgens cuidaremos disso. Como terminou tudo? Alguns dias depois chegaram da Itália cartas dos imperadores, tanto do próprio quanto de seu filho, que além de conter elogios, confirmava minha atéleia por dedicação à retórica, sempre que efetivamente me dedicasse a ela. Chegaram também, junto com a dos imperadores, outras cartas escritas por Heliodoro, que foi prefeito do Egito. Uma delas era para mim e a outra, em meu favor, era para o governador. Estas cartas, lisonjeiras e esplêndidas, haviam sido escritas muito antes de minhas dificuldades, mas chegaram oportunamente naquele momento (HL, 4.75). 
Apesar de Aristides ter se isentado das duas primeiras nomeações, foi na disputa com Severo que ele finalmente confirmou a atéleia. Severo não estava disposto a abrir mão de alguém de prestígio e fortuna como ele na distribuição das liturgias. Para recorrer da nomeação, Aristides lançou mão das cartas dos imperadores e de Heliodoro, às quais acrescenta as de Rufino, que havia sido cônsul em 142, e Pardalas, este também amigo de Severo:

E então o deus me chamou de novo a Pérgamo, onde precisamente se encontrava Rufino, o qual sempre estivera disposto a me honrar. Ao encontrar-me com ele, narrei detalhadamente o sucedido e solicitei sua ajuda. (...) A Rufino pareceu justo o que eu dizia e me entregou uma carta para o governador, escrita em sua própria língua, tão favorável a mim quanto possível. Nela eram expostos diversos argumentos: com alguns, me elogiava e, com outros, aconselhava Severo sobre o que no futuro aconteceria caso não aceitasse me liberar daqueles encargos (HL 4.83s).

Pardalas - nosso companheiro e também seu amigo íntimo, com quem mantinha grande familiaridade desde a infância - lhe havia escrito grandes maravilhas sobre meus discursos. Quando terminou de ler as cartas, [Severo] disse: 'Ninguém duvida de sua eloquência, mas uma coisa é ser o primeiro dentre os gregos quanto à retórica assim me identificou - e outra muito diferente é viver dessa profissão e ter alunos'. Após uma pausa, acrescentou: 'Apresente-se diante da assembleia e convença seus concidadãos' (HL 4.87).

Aristides mascara o que parece ser uma ameaça da parte de Rufino ao descrever seu encontro com ele em Pérgamo como uma coincidência provocada por Asclépio. Assim, ele enfatiza tanto seu lugar de favorito, quanto o poder de um amigo em causar prejuízo a Severo. A intervenção de Pardalas concluiu o quadro ao inserir na disputa um indivíduo íntimo do procônsul. Severo então lançou mão do sentido tradicional da legislação da atéleia, lembrando que Aristides não era professor. Para Vivian Nutton, o recurso de Aristides no processo pode ter se baseado na cláusula antonina sobre a isenção dos 'excepcionalmente instruídos' (Digesta, 27.1.6.10), mas o reconhecimento de alguém como parte dessa categoria era difícil de ser obtido e mantido (1971, 54). O discurso de Severo como elaborado por Aristides sugere que o procônsul valorizava a atéleia dos professores e dava ciência da isenção dos ă $\gamma \alpha \nu$ غ̇$\pi 1 \sigma \tau \eta ́ n o v \varepsilon \varsigma$, mas não reconhecia Aristides como um deles. Assim, Severo retirou-se da disputa ao lançar à assembleia a decisão sobre a categoria de Aristides, o qual então apresentou um longo discurso de apelação diante dele e dos cidadãos: 
Quando cheguei, tudo demonstrava o respeito devido a mim pelo próprio governador, seus conselheiros, pelos oradores ali reunidos e o público presente. A ocasião mais parecia a da apresentação de um discurso do que de um processo judicial. Era surpreendente a simpatia por mim, assim como a aprovação quanto às minhas palavras, demonstrada com aplausos e aclamações; comportavam-se como se escutassem por puro prazer. Meu discurso durou cinco clepsidras, e durante ele falei com toda a franqueza, e procurei dar a impressão de que o fazia como se estivesse diante do próprio imperador. Quando terminei, depois de um dos advogados da cidade me questionar com poucas e honrosas palavras, por respeito à assembleia e por considerar que assim eu obteria o mesmo resultado, considerando ser essa a melhor sentença, Severo me enviou novamente a ela com uma carta elogiosa. Assim foi confirmada a atéleia, e isso foi feito com tanta honra e amparo que nenhum dos demais que gozavam desse privilégio se comparava a mim. Quanto à outra magistratura à qual o governador me indicara, nem ele a mencionou, nem eu. Mas escreveu por iniciativa própria aos magistrados, ordenando-lhes que outra pessoa se encarregasse da tarefa e me substituísse (HL 4.91-93).

Não temos razão para duvidar do resultado na disputa, mas as condiçóes do episódio da assembleia chamam atenção, não apenas pela atuação de Severo, pressionado a favorecer Aristides, mas principalmente pela predisposição da audiência como descrita nos Hieroi Lógoi. Aparentemente, uma nova circunstância se definiu para ele. Quando Severo foi sucedido por Quadrato em 156, o novo procônsul reconfirmou a atéleia de Aristides após ler uma carta enviada por ele. Aristides relata que Quadrato a teria recebido no mesmo dia em que Asclépio lhe enviara um sonho no qual o sumo sacerdote do deus e seu avô, antigo ocupante do cargo, intercediam a seu favor, como amigos do procônsul (HL 4.63-67). A narrativa não nos permite afirmar uma intercessão de fato pelos sacerdotes junto a Quadrato, mas tem a função de abrir o longo relato sobre as disputas anteriores com um sinal da proteção divina e das associações e amizades por meio das quais Aristides se desvencilhou dos encargos litúrgicos.

\section{'SEgunda SOFística' e REDES de INFLUÊNCIA}

Aristides escreve em um momento particularmente privilegiado para a produção intelectual em cidades gregas sob dominação romana, de retorno a ideias e estilos clássicos. $\mathrm{O}$ movimento foi em grande medida fomentado pelo Império, desde Augusto até os Antoninos, e estendeu-se tanto geograficamente quanto em termos do volume de sua produção, marcadamente heterogênea 
(SILVA, 2007, 2). Seus autores partiam de práticas e modelos tradicionais atualizados de acordo com as novas necessidades imperiais. Parte da formação intelectual de grupos privilegiados, a oratória ultrapassou o campo da educação e do treinamento e se afirmou em discursos comemorativos e panegíricos em contextos de entretenimento público. Assim, já na segunda metade do século I, em cidades como Atenas, Esmirna e Éfeso, a declamação afirmava-se como uma das principais atividades culturais da vida urbana, com uma popularidade sem precedentes (BOWIE, 1970, 5). Na década de 230, Filóstrato representou esse fenômeno como um movimento unívoco e o denominou 'Segunda Sofística', porém a historiografia tem trabalhado no sentido de mostrar o equívoco dessa interpretação e discutir o quadro diversificado de seus autores e as circunstâncias de sua produção?.

No campo da oratória, a tradição literária será utilizada em espaços de poder, como foi o caso da corte de Julia Domna, por indivíduos cujos expedientes litúrgicos contribuíram para a renovação do prestígio e do vigor econômico de cidades como Atenas, Esmirna e Éfeso (BOWERSOCK, 1969, $17,26,101 \mathrm{~s})$. A elite intelectual dessas cidades estava intimamente envolvida na política imperial, pois seus ricos componentes e suas famílias constituíam o grupo do qual o Império servia-se para designar magistraturas, atribuindo a terceiros os dispendiosos custos de novas edificações, atividades religiosas e manutenção da ordem. Ao mesmo tempo, como parte das complexas atitudes gregas em relação a Roma, o arcaísmo pode ter figurado como um meio de alienação do tempo presente e, portanto, um sinal de resistência e da ambiguidade do comprometimento dos oradores perante a dominação imperial (BOWIE, 1970). Chamados à política nas mais diversas circunstâncias, esses intelectuais atuavam como embaixadores das cidades (entre elas e perante os imperadores e seus representantes), como membros das assembleias locais, em pronunciamentos públicos em situações críticas e em discursos durante festivais, cerimônias de dedicação de edifícios e de acolhida a visitantes ilustres. Porém, a percepção de perda da soberania pelas cidades e seus conselhos pode ter deixado vacantes espaços típicos da oratória pública clássica, agora preenchidos por temas e modelos tradicionais, como era o caso das narrativas míticas (BOWIE, 1970, 6).

Graham Anderson interpretou as prioridades de ascensão intelectual dos oradores como uma falta de interesse no potencial de proeminência política fornecido pelas ligações entre a retórica e o sistema de patronagem (1993, p. 236). Porém, o caso de Aristides coloca em evidência justamente o

9 Uma consistente referência, nesse sentido, é o levantamento bibliográfico produzido por Silva (2007). 
caráter político do que apenas parece ser uma inversão de prioridades. Seus empreendimentos no campo da política institucional são muito mais de evasão do que de participação. As estratégias para esse distanciamento, porém, iluminam seu caráter político. Os argumentos urdidos em torno da atuação profissional e da devoção a Asclépio e a própria busca pelas imunidades litúrgicas têm implicações na vida comum, a qual ultrapassa o campo das atitudes e envolvimentos institucionais (ANDRADE, 2002). Os recursos e expedientes dos quais Aristides lança mão configuram um problema político e devem ser interpretados como parte das relaçôes de forças no contexto das cidades gregas sob domínio imperial. Além disso, eles fazem parte do instrumental disponível a 'grupos de pressão' que não constituem necessariamente classes sociais e nem se reduzem a 'ricos e pobres', mas se configuram e sustentam em torno de interesses comuns mais ou menos duradouros a partir dos quais exercem influência sobre as autoridades detentoras do poder decisório (FINLEY, 1973, p. 116). Para além do contexto geopolítico maior, de uma Grécia sob domínio imperial romano, é preciso considerar tensões constituídas, intensificadas e modificadas para além dos poderes territoriais de âmbito formal. Nas cidades gregas da Ásia Menor, enquanto alguns indivíduos e grupos dispunham do instrumental utilizado por Aristides, uma parte majoritária de habitantes carecia de tão favoráveis laços de amizade que lhes habilitassem a costurar redes de eficiente amparo político, social e financeiro em momentos de disputas. As elites provinciais, no contexto de suas próprias comunidades, beneficiavamse de relações de desigualdade ao nelas estabelecer lugares de privilégios e isençôes que as reafirmavam no interior de redes de favorecidos. Em última instância, podiam mesmo ser alienadas dela, ao buscarem uma elevação muito acima de seus membros, a qual aproximava-os do imperador e, eventualmente, dos deuses.

\section{Autobiografia, auto-elogio \\ e PARTiCipação Na Vida pública}

Ao refletirmos sobre a narrativa da atéleia no contexto autobiográfico e aretalógico maior dos Hieroì Lógoi, devemos ter em mente que não é possível assumir a obra como a reprodução de um 'real' imediato, fora dela. $\mathrm{O}$ 'pacto autobiográfico' pelo qual se assume a identidade entre o autor, o narrador e o protagonista, jamais é plenamente direto ou estável, mas depende de um modo de escrita e de leitura (LEJEUNE, 1996, p. 14s). Além disso, a 'escrita de si' acompanha as contradições, fragmentações e dinamismos próprios ao 'eu', o 
qual não pode ser lido como uma unidade estável e coerente (LEVI, 1989, p. 169). A fim de produzir-se como texto e dar-se a ler ao público, a autobiografia, portanto, tem um caráter também inventivo, ficcional, pois acompanha o mesmo traçado de constituição da identidade e da vida (EAKIN, 1985, p. 3s, 182). Do ponto de vista do olhar historiográfico, esses três pressupostos nos oferecem recursos para construir relaçóes entre as narrativas de Aristides e seus interesses políticos, profissionais e religiosos.

Por meio de um discurso marcadamente elogioso, que toma a si mesmo como objeto, Aristides apresenta-se nos Hieroì Lógoi como um favorito do deus, e por isso um vitorioso inquestionável. Alguns dos mais importantes episódios a esse respeito giram em torno de suas condições de saúde, enquanto muitos outros incluem prodígios sobrenaturais. Sua primeira visão de Asclépio ocorreu durante um inverno rigoroso, quando visitou os Banhos de Agamêmnon (próximos de Esmirna), logo após ser declarado incurável pelos médicos. Aristides cumpriu sua ordem de caminhar descalço e, por isso, foi convidado para a estada no Asclepeion de Pérgamo (HL 2.7; 2.70; 3.44). Mesmo gravemente enfermo, ele cotidianamente superava suas desfavoráveis condições físicas, inclusive arriscando-se com terapias extremas e arriscadas (HL 1.73; 2.21s. Na obra, ele descreve uma grande intimidade com Asclépio, a qual por vezes alcança a identidade, condição necessária a realizar maravilhas como falar com animais e interromper terremotos (HL 1.17; 3.40; 3.50; 4.50ss). Sua superioridade em relação aos meros mortais a cercá-lo é tamanha que se envaidece pelas mortes pessoas próximas, interpretadas como barganhas pela extensão de sua própria vida (HL 5.22ss). Na vida pública não é diferente. Ele nasce em um meio privilegiado e exige ser tratado pelas cidades como alguém cujos direitos e deveres não são os mesmos a serem exigidos de outros particulares. Aristides se mostra como alguém cuja distinção, interpretada como de ordem sobrenatural, deve isentá-lo de qualquer responsabilidade e, segundo sua autobiografia, é totalmente vitorioso em seu intento.

É sintomático da natureza retórica dos Hieroì Lógoi que a narrativa sobre as cartas dos imperadores e de Heliodoro ocorra logo após a súplica de Aristides a Asclépio sobre como agir diante da nomeação de Severo, respondida, em sonhos, pelo oráculo délfico que lhe garante a solução do caso por meio de intervenção divina. Desta forma, Aristides caracteriza a defesa por parte das altas estruturas do poder romano como resultado direto da atenção e do interesse Asclépio por ele. A narrativa sobre esses eventos assim indica que a lealdade de Aristides reside, em primeiro lugar, ao lado do deus, e por isso seu status encontra-se para além dos limites da sociedade (DOWNIE, 2008, 187). Assim, estamos inclinados a pensar as negativas de Aristides como algo além de uma mera mesquinharia insistente. 
No mencionado epitáfio em honra a Alexandre, escrito entre os anos 146 e 153, Aristides enaltece seu mestre como benfeitor de Cotieu, responsável por financiar a restauração de seus monumentos (EA 5, 17ss). Para elogiá-lo, lança mão justamente do termo $\mu \varepsilon \gamma \alpha \lambda$ o $\psi v \chi i ́ \alpha \varsigma$, 'grandeza de alma'. Disposto a tratar a questão do evergetismo, por meio da referência a seu mestre, Aristides oculta do texto o procedimento institucional por meio do qual Alexandre disponibilizou tanto de suas riquezas à cidade. Pelo epitáfio, não é possível saber se ele foi indicado a alguma liturgia, ou se custeou as obras por livre e espontânea vontade. Aristides assim evita o espinhoso tema das liturgias e do envolvimento formal com os assuntos públicos.

Apesar de sua evasão institucional, Aristides foi lembrado por Filóstrato como benfeitor de Esmirna, por ter intercedido a favor da cidade e convencido Marco Aurélio a reconstruí-la após o terremoto que a devastou em 178 (ARISTIDES, Monodia por Esmirna; FILÓSTRATO, VS 582s). Para tanto, não precisou mobilizar sua fortuna, como fez Alexandre, mas sua rede de influências, e assim pôde afirmar uma memória positiva a seu próprio respeito. Uma inscrição esmírnea pode estar relacionada ao episódio: aparentemente doada pelas cidades de Alexandria, Hermópolis, Antinópolis, e pelos habitantes das regióes do Delta do Egito e da Tebaida, ela elogiava Aristides por suas virtudes ( $\alpha \nu \delta \rho \alpha \gamma \alpha \theta i ́ \alpha 1)$. Marie-Henriette Quet (1992, p. 392ss) a interpretou como uma iniciativa dos habitantes de Esmirna, os quais teriam recuperado os originais decretos honoríficos a Aristides emitidos pelas cidades citadas e os condensado em uma nova inscrição. Assim, podemos localizar Aristides em uma dinâmica mais ampla de atuação em favor das cidades do que sua forma institucionalizada por meio das liturgias, a qual o isenta de gastos, mas o remete a um contexto de favorecimentos e relações privilegiadas.

A leitura do Epitáfio a Alexandre também remete ao problema das atividades de ensino de Aristides. A atuação de Alexandre como professor é elogiada ao longo de todo o discurso, e há um destaque quanto a ele, por um lado, nunca ter exigido retribuição por suas beneficências, ao mesmo tempo que não se envergonhava de receber pagamento por suas aulas. Porém, Aristides enfatiza que seu mestre não cobrava a quem fosse desprovido de meios para pagá-lo e, inclusive, provia-lhes de amparo financeiro (EA 16). Esses argumentos, logo antes da narrativa sobre as restauraçóes de Cotieu, pretendem enfatizar a generosidade de Alexandre, o qual, para Aristides, deveria ser considerado o benfeitor da cidade mesmo se com ela não tivesse gasto qualquer dinheiro (EA 19). A indefinição da época de composição do 
discurso (COPETE, 1997, p. 423) não nos permite afirmar uma relação direta com as disputas pela atéleia, porém, ele figura como um ponto significativo de reflexão sobre o tema da participação na vida pública. Parece estar em jogo, ali, uma valorização das modalidades extraoficiais e não-financeiras de benefício.

$\mathrm{Na}$ conclusão de seu encontro com Severo, o procônsul aconselha Aristides a assumir alunos, a fim de resguardar-se de novas liturgias. Aristides o fará justamente ao final daquele processo, em 153, o mais famoso deles identificado por Filóstrato como o sofista Damiano (VS 582). Filóstrato também narra um encontro em Esmirna ocorrido em 176 entre Marco Aurélio e Aristides, no qual ele pode ter sido acompanhado por seus pupilos (VL 583; Pernot, 2008, 182). O termo utilizado por Filóstrato para narrar o episódio foi $\gamma v \omega \rho i ́ n o v \varsigma$, traduzido na edição inglesa de Wright como 'students'. Raffaella Cribiore contesta a atribuição e recupera os sentidos de 'amigo' ou 'conhecido', de forma que a passagem pode ser uma referência aos companheiros de Aristides, não necessariamente seus alunos, ainda que Filóstrato os tenha interpretado assim (2008, p. 276). Nos Hieroì Lógoi, há poucas menções ao ensino, e elas não indicam que Aristides tenha de fato assumido alunos até a época da composição da obra. Ele menciona duas vezes o interesse dos habitantes de Esmirna de que ele ensinasse aos jovens: na ocasião de sua indicação como coletor de impostos na década de 150, e após uma viagem a Pérgamo ocorrida em 167 (4.95; 5.29). Outra passagem refere-se a um sonho, cerca de 175, em que um amigo o exorta a assumir alunos (5.57). Aristides, no entanto, não esclarece os desdobramentos dessas solicitações, e é possível que elas figurem na obra apenas como um recurso retórico cujo objetivo é afirmar sua fama como orador e sugerir a possibilidade da atuação como professor. Essa indefinição aponta no sentido de suas atividades pedagógicas serem raras e passassem ao largo da prática das cidades de nomearem alguns professores para atividades públicas (ISRAELOWICH, 2016, p. 241). Sua recusa em aceitar pagamento (elogiada no Epitáfio a Alexandre e mencionada por Filóstrato) sugere sua negativa em assumir maiores compromissos com o ensino. Quando mais tarde Galeno o caracteriza como alguém ativo no ensino e na oratória, devemos ter em conta que, muito possivelmente, ele tinha de Aristides a memória construída sobre ele por seu mestre, Sátiro (Comentário ao Timeu apud BEHR, 1968, p. 162). Como médico de Aristides, Sátiro pode ter-lhe transmitido informações sobre os discípulos de seu paciente, sem caracterizar suas atividades de ensino do ponto de vista quantitativo, assim deixando livre espaço à interpretação, por Galeno, de seus relatos. 


\section{Conclusão}

De acordo com os Hieroì Lógoi, Aristides conseguiu reverter a situação de embaraço político na qual se encontrava por meio do favorecimento divino. Como observa Israelowich, não the interessava apresentar-se como um profissional do ensino, nem de identificar-se com qualquer categoria definida por lei, pois a escolha de Asclépio de tê-lo como protegido tornava único seu status como orador (2016, p. 247). Mas esse status tinha consequências diretas para a cidade. Ao evadir-se das liturgias e não assumir alunos de forma expressiva, Aristides isenta-se da responsabilidade de, como homem rico e bem relacionado que é, trabalhar em benefício dos locais onde habita e detém propriedades, sua recém-fundada cidade de origem e a prestigiosa Esmirna. Downie interpreta suas disputas com os procônsules como um efeito dos interesses financeiros de Arisitides e sua irresponsabilidade com as cidades (2008, 183ss). Essa é uma leitura superficial dos episódios narrados e de sua atitude geral para com a vida pública. Devemos olhar para além dessa dita mesquinharia e irresponsabilidade e observar como elas se fundamentam.

Foi construída uma memória literária e epigráfica em torno de Aristides a qual fez dele um cidadão ativo e generoso, mas notamos que sua magnificência tem o limite das conveniências e não passa por responsabilidades formais. Os Hieroì Lógoi nos induzem a acompanhá-lo em sua interpretação sobre si mesmo de que tal evasão pública corresponde à impossibilidade de esquivarse às responsabilidades para com Asclépio, única autoridade reconhecida por ele. A obra assim o constrói como alguém a quem deveriam ser outorgados direitos excepcionais, mas essa excepcionalidade tem consequências diretas para as cidades, ocultas no discurso autobiográfico. Não conhecemos sua dimensão, mas podemos prever pela legislação de limitação da atéleia que os encargos litúrgicos figuravam como uma necessidade compreendida como legítima e eficiente, na medida em que as comunidades a percebiam e definiam como tal (FINLEY, 1983, p. 35).

$\mathrm{Na}$ década de 1970, Paul Veyne argumentou contra a interpretação das liturgias como um imposto indireto, um recurso redistributivo das cidades com vistas a amenizar desequilíbrios sociais, ao destacar que apenas em ocasióes pontuais elas complementaram os rendimentos das cidades. Porém, discordamos da extensão de seu argumento quando ele declara as liturgias como uma instituição do supérfluo (1976, p. 215s). Não podemos interpretar os encargos atribuídos a Aristides como recursos fúteis ou meramente simbólicos, nem estamos no lugar de julgar a eficiência material e o benefício 'real' trazido pelas liturgias, no entanto é evidente sua importância 
política, visto que as cidades insistem nas nomeações e disputam com ele contra suas tentativas de garantir a atéleia. Não. Chamam atenção os recursos retóricos usados por Aristides ao compor uma memória de sua evasão dessas responsabilidades, e é significativo que ele tenha passado cerca de dez anos, entre a primeira e a última nomeação, sem admitir alunos e, assim, ter um argumento jurídico válido a favor da atéleia. $\mathrm{Na}$ época de Aristides, o ensino profissionalizado constituía uma demanda incontornável da administração imperial, a qual exigia letramento e, portanto, professores. William Harris observa que essa necessidade era satisfeita por meio de um quadro profissional de acesso público em escolas, ao invés da atuação pontual de tutores (1989, p. 196s; 233). Os Hieroì Lógoi nos sinalizam a negativa de Aristides em envolverse formalmente com essas atividades.

A atuação de Severo é fundamental para interpretarmos a narrativa da atéleia e o conteúdo dos interesses populares que ela busca ocultar pelos recursos retóricos de Aristides. $\mathrm{O}$ procônsul isenta-se de tomar uma decisão desfavorável à do imperador, mas ao mesmo tempo não pode abrir mão de convocar o conselho da cidade para apreciar a questão. Por meio da assembleia, eles permitem a construção de uma narrativa de harmonia e legitimidade entre as decisões do imperador e os interesses da cidade quanto à imunidade de Aristides, que teria sido recebido e ouvido com simpatia. Porém, um detalhe importante sobre a ocasião e provavelmente conhecido pela audiência dos Hieroì Lógoi não pôde ser ocultado, e é superficialmente incluído algumas passagens antes. Logo ao chegar à assembleia, Aristides teve seu nome apontado à pritania (HL 4.88). A assembleia, assim, não nos parece tão favorável a reconhecer a atéleia de Aristides como a seguir ele insistirá em afirmar, e já podíamos desconfiar disso ao lê-la de maneira mais cética do que pretende o autor. $\mathrm{O}$ documento nos traz uma narrativa cujos propósitos e potencial audiência que devemos desvendar. Aristides e Severo parecem ter interesse em uma memória do episódio segundo a qual a cidade cedeu à atéleia sem grandes resistências. Os Hieroi Lógoi não nos deixam espaço para conhecer uma narrativa contraditória à encaminhada por Aristides, que nos permitiria identificar outros olhares sobre as tensões ali relatadas e outros protagonismos.

$\mathrm{Na}$ narrativa da atéleia, Aristides representa-se como um injustiçado e, quando finalmente é vitorioso em suas disputas com as cidades, envaidece-se de sua astúcia, dos amigos poderosos dos quais dispõe e dos prodígios divinos sempre favoráveis a ele. Pensados do ponto de vista ético, os recursos políticos de Aristides ao longo dos processos trazem ao debate cotidianas corrupçóes que estão na base de indivíduos e grupos para se compreendem como 
excepcionais e atuam por fora das instituições para fazer valer seus caprichos e sobrepujar a lei sempre que isso se faz conveniente. Na superfície de um ideal meritocrático retroalimentado por favorecimentos e tráficos de influência, os Hieroì Lógoi desdobram argumentos de eleição divina e prodígios executados pelo deus Asclépio em benefício de seu autor. Como uma autobiografia, eles nos apresentam o ponto de vista do membro de uma elite muito privilegiada, cujo protagonismo narrativo nas cidades é disputado com seus habitantes que, muitas vezes, buscam os meios institucionais de fazer valer seus direitos, mas falham. Do ponto de vista do autor-protagonista e a serviço de outros como ele, os Hieroì Lógoi são uma história de sucesso individual e dos desígnios metafísicos que amparam seus extraordinários méritos mundanos. Porém, do ponto de vista das coletividades, a obra é uma história de alienação e derrota, de silenciamento dos que não fazem parte de uma rede favorável de influências e sociabilidades ou não dispóem de recursos para manipulá-la de maneira eficiente e, finalmente, não podem construir eles mesmos o protagonismo narrativo de seus próprios conflitos.

\title{
ARISTIDES AND THE CITIES: ATELEIA AND THE EVASION FROM LITURGIES IN ASIA MINOR, CA. 170 C. E.
}

\begin{abstract}
The ways of evasion from responsibilities attached to public goods enable - to some resourceful individuals - privileges and exemptions that withdraw them from among the mass of 'commons', these equally submitted to the law and with access to the same corpus of rights that normalizes them in everyday life dynamics. Aelius Aristides, based in Smyrna, was nominated to several liturgies between the 140's and the 150's E.C., as he writes in the Hieroi Lógoi. Through them, the province and the cities sought to ensure the administration of many sectors of social life through costly offices assigned to particulars. Aristides was not eligible as a professional exempted by law, therefore he appealed to his personal network of influences, which included the emperor Marcus Aurelius, and through it guaranteed the ateleia (immunity). We intend to discuss the political resources used by him and the meanings and effects of his evasion.
\end{abstract}

Keywords: Aelius Aristides; liturgies; ateleia; influence networks.

\section{REFERÊNCIAS}

\section{Documentação}

ARISTIDES. Discursos IV. Tradução de Juan Manuel Cortés Copete. Madrid: Gredos, 1997.

ARISTIDES. Discursos V. Tradução de Juan Manuel Cortés Copete. Madrid: Gredos, 1999. 
ARISTÓTELES. Política. Brasília: UNB, 1985.

DEMOSTHENES. Orations II. Tradução de James Vince. Cambridge: Harvard UP, 1926.

DION CASIO. Historia Romana L-LV. Tradução de Juan Manuel Cortés Copete. Madrid: Gredos, 2011.

MOMMSEN, Theodor (ed.). The Digest of Justinian. Philadelphia: University of Pensilvania Press, (1870) 1985.

PHILOSTRATUS. The lives of the sophists. Tradução de Wilmer Wright. London: William Heinemann, 1922.

SUDA. Aristeides, A3902. Suda on line. Tradução de Malcolm Heath. 09/04/2017 <http://www.stoa.org/sol-entries/alpha/3419>.

\section{Bibliografia}

ANDERSON, Graham. The Second Sophistic: a Cultural Phenomenon in the Roman Empire. London: Routledge, 1993.

ANDRADE, Marta Mega de. A vida comum. Espaço, cotidiano e cidade na Atenas clássica. Rio de Janeiro: DP\&A, 2002.

BEHR, Charles Allison. Aelius Aristides and the Sacred Tales. Amsterdam: Adolf M. Hakkert, 1968.

BOMPAIRE, Jacques. Quatre styles d'autobiographie au $\mathrm{II}^{\mathrm{e}}$ siècle après J.-C. In: PERNOT, Laurent et al (org.). L'invention de l'autobiographie d'Hésiode à Saint Augustin. Paris: École Normale Supérieure 1993, p. 199-209.

BOWERSOCK, Glen. Greek Sophists in the Roman Empire. Oxford: Clarendon, 1969.

BOWERSOCK, Glen. Philostratus and the Second Sophistc. In: The Cambridge History of Classical Literature, vol. I, 1985, pp. 655-662.

BOWIE, Ewen. Greeks and their Past in the Second Sophistic. Past \& Present, Oxford, v. 46, 1970, p. 3-41.

CADOUX, Cecil. Ancient Smyrna. Oxford: Blackwell, 1938.

CORBIER, Mireille. La niñez en Roma: leyes, normas, prácticas individuales y colectivas. Auster. N. 5, 2000, p. 11-45.

CRIBIORE, Raffaella. Vying with Aristides in the fourth century: Libanius and his friends. In: HOLMES, Brooke; HARRIS, William. Aelius Aristides between Greece, Rome and the Gods. Leiden: Brill, 2008, pp. 263-278.

DAVIES, John Kenyon. Demosthenes on liturgies: a note. Journal of Hellenistic Studies, Cambridge, v. 87, 1967, p. 33-40.

DOWNIE, Janet. Professing Illness: healing narrative and rhetorical selfpresentation in Aelius Aristides' Hieroi Logoi. Ph.D. diss. Chicago: University of Chicago, 2008.

EAKIN, Paul John. Fictions in autobiographyः studies in the art of self-invention. New Jersey: Princeton University Press, 1985.

FINLEY, Moses. Democracia antiga e moderna. Rio de Janeiro: Graal, (1973) 1985.

FINLEY, Moses. Politics in the Ancient World. Cambridge: Cambridge UP, 1983. GUERRA, Lolita. Noturno vagar: o Eu mortal imortal nos Hieroi Lógoi de Élio Aristides. Tese de doutorado. Campinas: UNICAMP, 2014. HARRIS, William. Ancient literacy. Cambridge: Harvard UP, 1989. 